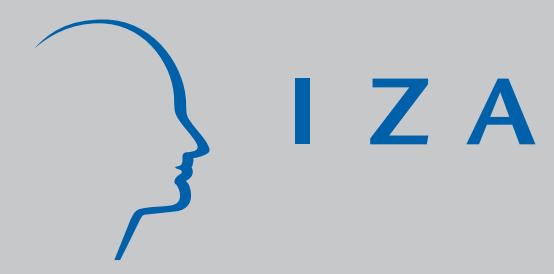

IZA DP No. 159

\title{
Preemptive Behavior in Sequential Tournaments
}

Peter -J. Jost

Matthias Kräkel

May 2000 


\title{
Preemptive Behavior in Sequential Tournaments
}

\author{
Peter - J. Jost \\ Institute for Organization Theory, WHU, Koblenz \\ Matthias Kräkel \\ Department of Economics, University of Bonn and IZA, Bonn \\ Discussion Paper No. 159 \\ May 2000 \\ IZA \\ P.O. Box 7240 \\ D-53072 Bonn \\ Germany \\ Tel.: +49-228-3894-0 \\ Fax: +49-228-3894-210 \\ Email: iza@iza.org
}

This Discussion Paper is issued within the framework of IZA's research area The Future of Work. Any opinions expressed here are those of the author(s) and not those of the institute. Research disseminated by IZA may include views on policy, but the institute itself takes no institutional policy positions.

The Institute for the Study of Labor (IZA) in Bonn is a local and virtual international research center and a place of communication between science, politics and business. IZA is an independent, nonprofit limited liability company (Gesellschaft mit beschränkter Haftung) supported by the Deutsche Post AG. The center is associated with the University of Bonn and offers a stimulating research environment through its research networks, research support, and visitors and doctoral programs. IZA engages in (i) original and internationally competitive research in all fields of labor economics, (ii) development of policy concepts, and (iii) dissemination of research results and concepts to the interested public. The current research program deals with (1) mobility and flexibility of labor markets, (2) internationalization of labor markets and European integration, (3) the welfare state and labor markets, (4) labor markets in transition, (5) the future of work, (6) project evaluation and (7) general labor economics.

IZA Discussion Papers often represent preliminary work and are circulated to encourage discussion. Citation of such a paper should account for its provisional character. 
IZA Discussion Paper No. 159

May 2000

\section{ABSTRACT \\ Preemptive Behavior in Sequential Tournaments}

Rank-order tournaments are usually modeled simultaneously. However, real tournaments are often sequentially. We show that agents' strategic behavior significantly differs in sequential tournaments compared to simultaneous tournaments. In a sequential tournament, under certain conditions the first acting agent chooses a preemptively high effort so that the following agent gives up. In general, the principal will prefer simultaneous tournaments in which preemptive behavior is impossible.

JEL Classification: J31, J33, J41

Keywords: Preemptive behavior, rank-order tournaments, sequential tournaments

Matthias Kräkel

Department of Economics, BWL II

University of Bonn

Adenauerallee 24-42

53113 Bonn

Germany

Tel.: + 49-228-73 9211

Fax: +49-228-739210

Email: m.kraekel@uni-bonn.de 


\section{Introduction}

Rank-order tournaments have been extensively discussed in the literature. ${ }^{1}$ In the basic model, two agents compete for tournament prizes by choosing their effort levels simultaneously. The agent who produces the highest output receives the winner prize whereas the other agent gets the loser prize. The main result of this literature is that, under certain circumstances, the principal can design tournament prizes such that the agents choose the first-best effort level. Moreover, further advantages have been attributed to tournaments; especially, low measurement costs, the filtering of common noise, and contractibility even in cases where agents' efforts and outputs are unverifiable.

The common assumption of all these tournament models is that the competing agents choose their effort levels simultaneously. This assumption may hold in some contexts. In many other contexts, however, agents do not decide about their efforts at the same time. In addition, real tournaments are dynamic and agents may be able to observe their competitors' efforts when deciding on their own effort. Hence, the agents may get some information during the tournament, which will influence their succeeding effort choices. Obviously, these features cannot be discussed within a simultaneous tournament.

In this paper, we consider tournaments in which the agents are assumed to choose their efforts sequentially. In a two-agent tournament, one of the agents first chooses his effort. After that, the other agent observes this effort and then has to decide about his own effort level. This sequential tournament substantially differs from the standard simultaneous tournament. In particular, the sequential tournament allows for additional strategic behavior by the agents: The first acting agent has the chance to discourage the second agent 
by choosing a preemptively high effort level. ${ }^{2}$ This, in turn, implies that the principal may be unable to implement first-best effort levels, because it leads to inefficient agents' behavior in the tournament.

In a paper by Jost (2000) is it shown that intermediate information will not alter the agents' decisions if the agents' outputs depend on luck rather than effort. This is due to the fact that in this case the agent with the highest effort will not necessarily realize the highest output. Hence, the second agent still has the chance to win the tournament, even if he chooses the lower effort level. As a consequence, the first agent cannot strategically use his firstmover advantage: Choosing a preemptive effort level to push the other agent out of the contest is too costly compared to his increased winning probability.

The purpose of this paper is to analyze sequential tournaments in situations in which the agents' outputs depend on effort rather than luck. Two cases are distinguished: First, we consider a situation in which the agents' luck is restricted. In particular, we assume that luck is a random variable, distributed by a function with finite support. We show that in this case a preemptive effort by the first acting agent is possible and depends on the tournament prizes as well as on the agent's cost function. This implies for the principal that he weakly prefers a simultaneous tournament to a sequential one.

Second, we consider a situation in which the agents' luck is irrelevant for winning the tournament. In particular, we assume that the agents' outputs are determined only by their effort levels. In this case, we show that either the first acting agent chooses a preemptive effort and the second agent gives up, or that the first agent resigns from the tournament and the second agent wins with an arbitrarily small effort. As an immediate consequence, the principal strictly prefers a simultaneous tournament to a sequential tournament. 
The paper is organized as follows: As a benchmark we introduce in Section 2 the basic model of simultaneous tournaments and sketch the main result. In Section 3, we alter the time structure of the simultaneous tournament and discuss a sequential tournament in which luck is restricted. Section 4 then considers the case of the sequential tournament in which only the agents' efforts determine their outputs. Section 5 concludes.

\section{Simultaneous tournaments}

We follow the model of Lazear and Rosen (1981) and consider a tournament between two homogeneous and risk neutral agents. According to the ranks of their outputs the agents receive a winner prize $w_{1}$ or a loser prize $w_{2}$, where $w_{1}>w_{2}$. The output $q_{i}$ of agent $i(i=A, B)$ is given by the linear production function

$$
q_{i}=e_{i}+\varepsilon_{i}
$$

where $e_{i} \geq 0$ denotes agent $i$ 's effort. The error terms $\varepsilon_{A}$ and $\varepsilon_{B}$ are independently and identically distributed over the interval $[-\bar{\varepsilon}, \bar{\varepsilon}]$ with cumulative distribution function $F(\varepsilon)$ and density $f(\varepsilon)$. The principal, who is also risk neutral, is assumed to observe neither $e_{i}$ nor $\varepsilon_{i}$. But he can observe the unverifiable output $q_{i} \cdot{ }^{3}$ Effort $e_{i}$ entails some costs for agent $i$. These costs can be described in monetary terms by the function $c\left(e_{i}\right)$ with $c(0)=0$, $c^{\prime}\left(e_{i}\right)>0$, and $c^{\prime \prime}\left(e_{i}\right)>0$. The principal maximizes his expected surplus, i.e. the sum of the expected outputs $\left(E\left(q_{A}\right)+E\left(q_{B}\right)\right)$ minus the labor costs $w_{1}+w_{2}$. According to this objective function he chooses appropriate tournament prizes to generate optimal incentives for the two agents. Each agent maximizes his expected tournament prize minus his effort $\operatorname{costs} c\left(e_{i}\right)$. If 
agent $i(i=A, B)$ decides to participate in the tournament, he will at least receive a reservation utility $\bar{u}$.

To sum up, there is two-stage game between the principal and the two agents (see Figure 1). In stage 1, the principal chooses the prizes $w_{1}$ and $w_{2}$ to maximize his expected surplus. In stage $2-$ the tournament stage agent $A$ and agent $B$ simultaneously choose their efforts $e_{A}$ and $e_{B}$. After realization of $q_{A}$ and $q_{B}$, the most successful agent gets $w_{1}$, whereas the other receives $w_{2}$.

\section{[Figure1]}

To analyze this game, we consider first the tournament stage. Agent $i$ $(i, j=A, B ; i \neq j)$ exerts effort $e_{i}$ to maximize

$$
\begin{aligned}
E U_{i}\left(e_{i}\right) & =w_{2}+\Delta w \cdot \operatorname{prob}\left\{q_{i}>q_{j}\right\}-c\left(e_{i}\right) \\
& =w_{2}+\Delta w \cdot F_{Y}\left(e_{i}-e_{j}\right)-c\left(e_{i}\right)
\end{aligned}
$$

with $\Delta w:=w_{1}-w_{2}$ as prize spread, $Y:=\varepsilon_{j}-\varepsilon_{i}$ and $F_{Y}(\cdot)$ as $Y$ 's distribution function. The density of the composed random variable is denoted by $f_{Y}(\cdot)$. Agent $j$ 's objective function is given by

$$
E U_{j}\left(e_{j}\right)=w_{2}+\Delta w \cdot\left[1-F_{Y}\left(e_{i}-e_{j}\right)\right]-c\left(e_{j}\right)
$$

The first order conditions yield

$$
\begin{aligned}
& \Delta w \cdot f_{Y}\left(e_{i}-e_{j}\right)=c^{\prime}\left(e_{i}\right) \\
& \Delta w \cdot f_{Y}\left(e_{i}-e_{j}\right)=c^{\prime}\left(e_{j}\right) .
\end{aligned}
$$

Hence, when a Nash equilibrium exists, it has to be symmetric, i.e. $e_{i}^{*}=$ $e_{j}^{*}=e^{*}$, and each agent will become the winner of the tournament with probability $1 / 2 .{ }^{4}$ Therefore, from the principal's viewpoint in stage 1 each 
agent's incentive constraint for given tournament prizes is given by

$$
\Delta w \cdot f_{Y}(0)=c^{\prime}\left(e^{*}\right)
$$

and his participation constraint by

$$
\frac{w_{1}+w_{2}}{2}-c\left(e^{*}\right) \geq \bar{u}
$$

Thus, the principal's maximization problem leads to the Lagrangian function

$$
\begin{aligned}
L\left(w_{1}, w_{2}, e^{*}\right)= & 2\left(e^{*}+E(\varepsilon)\right)-w_{1}-w_{2} \\
& +\lambda_{1} \cdot\left[\Delta w f_{Y}(0)-c^{\prime}\left(e^{*}\right)\right]+\lambda_{2} \cdot\left[\frac{w_{1}+w_{2}}{2}-c\left(e^{*}\right)-\bar{u}\right] .
\end{aligned}
$$

The optimality conditions for $e^{*}, w_{1}$, and $w_{2}$ show that $\lambda_{1}=0$ and $\lambda_{2}=$ 2 (i.e., the participation constraint is binding). Moreover, we obtain the following results: ${ }^{5}$

Proposition 1 In the simultaneous tournament, the principal chooses

$$
w_{1}=c\left(e^{*}\right)+\bar{u}+\frac{c^{\prime}\left(e^{*}\right)}{2 f_{Y}(0)}
$$

and

$$
w_{2}=c\left(e^{*}\right)+\bar{u}-\frac{c^{\prime}\left(e^{*}\right)}{2 f_{Y}(0)}
$$

and implements first-best effort $e^{*}=c^{-1}(1)$.

Proposition 1 describes the benchmark result for simultaneous tournaments with risk neutral agents: Since there is no trade-off between incentives and risk sharing, the first-best solution will always be achieved. Ex ante, each agent is rewarded by an expected prize $\left(w_{1}+w_{2}\right) / 2$ which exactly compensates him for this effort costs $c\left(e^{*}\right)$ and his reservation utility $\bar{u}$. Ex post, however, the winner is strictly better off than the loser. This induces optimal incentives to generate first-best efforts. The following section discusses whether the first-best solution can also be achieved in the sequential tournament. 


\section{Sequential tournaments with restricted luck}

In this section, we drop the assumption that both agents simultaneously choose their efforts. Instead, the following three-stage game is considered (see Figure 2).

[Figure2]

Again, in stage 1 the principal decides about prizes $w_{1}$ and $w_{2}$, and effort level implementation. In stage 2 , agent $A$ chooses $e_{A}$. In stage 3 , agent $B$ observes $e_{A}$ and then chooses $e_{B}$. As in the simultaneous case, the realizations of $\varepsilon_{A}$ and $\varepsilon_{B}$ are not known by either agent when exerting effort.

As in Section 2, we assume that the $\varepsilon_{i}$ are distributed over a finite interval $[-\bar{\varepsilon} ; \bar{\varepsilon}]$. The convolution $f_{Y}(y)$ can be described by ${ }^{6}$

$$
f_{Y}(y)=\left\{\begin{array}{cc}
\int_{-\bar{\varepsilon}}^{y+\bar{\varepsilon}} f(\varepsilon) f(\varepsilon-y) d \varepsilon & \text { if }-2 \bar{\varepsilon} \leq y \leq 0 \\
\int_{y-\bar{\varepsilon}}^{\bar{\varepsilon}} f(\varepsilon) f(\varepsilon-y) d \varepsilon & \text { if } 0<y \leq 2 \bar{\varepsilon} \\
0 & \text { otherwise }
\end{array}\right.
$$

Therefore, using (5) (or (4)) agent $B$ 's reaction function in stage 3 can be written as $e_{B}=e_{B}\left(e_{A}, \Delta w\right)$ with $^{7}$

$$
\begin{aligned}
\Delta w \int_{-\bar{\varepsilon}}^{e_{B}-e_{A}+\bar{\varepsilon}} f(\varepsilon) f\left(\varepsilon-e_{B}+e_{A}\right) d \varepsilon & =c^{\prime}\left(e_{B}\right) \text { if }-2 \bar{\varepsilon} \leq e_{B}-e_{A} \leq 0 \\
\Delta w \int_{e_{B}-e_{A}-\bar{\varepsilon}}^{\bar{\varepsilon}} f(\varepsilon) f\left(\varepsilon-e_{B}+e_{A}\right) d \varepsilon & =c^{\prime}\left(e_{B}\right) \text { if } 0<e_{B}-e_{A} \leq 2 \bar{\varepsilon} \\
e_{B} & =0 \quad \text { if } e_{A}>2 \bar{\varepsilon}
\end{aligned}
$$

Expression (10) describes the possibility that agent $B$ will become completely discouraged, if agent $A$ chooses a preemptive effort $e_{A}>2 \bar{\varepsilon}$. In stage 2 , agent $A$ has to decide about his effort choice for given tournament prizes and anticipating that $B$ will behave according to (8)-(10). Again, using (4) (or (5)) yields the best response $e_{A}$ of agent $A$. If $-2 \bar{\varepsilon} \leq e_{B}-e_{A} \leq 0$ or 
$0<e_{B}-e_{A} \leq 2 \bar{\varepsilon}$, substituting $c^{\prime}\left(e_{B}\right)$ by $c^{\prime}\left(e_{A}\right)$ in (8) and (9), respectively, will characterize agent $A$ 's effort choice. As an alternative, Agent $A$ can choose preemptive effort $e_{A}=2 \bar{\varepsilon}^{8}$ to induce $e_{B}=0$ according to (10). In the two scenarios described by (8) and (9), we obtain the well-known result from simultaneous tournaments: Since the agents' marginal benefits from increasing their efforts are identical, marginal costs must be identical, that is $c^{\prime}\left(e_{B}\right)=c^{\prime}\left(e_{A}\right)$. Hence, efforts must also be identical, i.e. $e_{B}=e_{A}=e^{* *}$. But then $e_{B}-e_{A}=0$ implies

$$
\Delta w \int_{-\bar{\varepsilon}}^{\bar{\varepsilon}} f^{2}(\varepsilon) d \varepsilon=c^{\prime}\left(e^{* *}\right) \stackrel{(7)}{\Leftrightarrow} \Delta w f_{Y}(0)=c^{\prime}\left(e^{* *}\right) .
$$

Comparing (11) with the results for the simultaneous tournament from Section 2 gives $e^{* *}=e^{*}$, i.e. the two agents will choose the same effort as in the case of simultaneous tournaments. Whether agent $A$ chooses $e_{A}=e^{*}$ or the preemptive effort $e_{A}=2 \bar{\varepsilon}$ depends on his expected utility $E U_{A}\left(e_{A}\right)$ in these cases: Since

$$
E U_{A}\left(e^{*}\right)=w_{2}+\Delta w\left[1-F_{Y}(0)\right]-c\left(e^{*}\right)=w_{2}+\frac{\Delta w}{2}-c\left(e^{*}\right)
$$

and

$$
E U_{A}(2 \bar{\varepsilon})=w_{2}+\Delta w\left[1-F_{Y}(-2 \bar{\varepsilon})\right]-c(2 \bar{\varepsilon})=w_{2}+\Delta w-c(2 \bar{\varepsilon}),
$$

we obtain the following proposition:

Proposition 2 In the sequential tournament, in which luck is distributed over a finite interval $[-\bar{\varepsilon}, \bar{\varepsilon}]$, the agents' optimal behavior is as follows:

(a) $e_{A}=2 \bar{\varepsilon}$ and $e_{B}=0$ when

$$
\frac{\Delta w}{2}>c(2 \bar{\varepsilon})-c\left(e^{*}\right)
$$


(b) $e_{A}=e_{B}=e^{*}$ when

$$
\frac{\Delta w}{2}<c(2 \bar{\varepsilon})-c\left(e^{*}\right)
$$

where

$$
e^{*}:=c^{\prime-1}\left(\Delta w \int_{-\bar{\varepsilon}}^{\bar{\varepsilon}} f^{2}(\varepsilon) d \varepsilon\right) .
$$

Proposition 2 shows that in case (a) agent $A$ prefers to choose a preemptive effort to discourage agent $B$ : Thus, Proposition 2 characterizes a sufficient condition for sequential tournaments to differ strategically from simultaneous tournaments. Inequality (14) is also intuitively plausible. Agent $A$ will prefer $e_{A}=2 \bar{\varepsilon}$ to $e_{A}=e^{*}$, if the additional gain $\Delta w / 2\left(=w_{1}-\left[w_{1}+w_{2}\right] / 2\right)$ exceeds the additional costs $c(2 \bar{\varepsilon})-c\left(e^{*}\right)$ from exerting the preemptively high effort.

Proposition 2 leads to the following comparative-static results: First, there exists a critical value $\bar{\varepsilon}^{*}$ such that for every distribution $f(\cdot)$ over $[-\bar{\varepsilon}, \bar{\varepsilon}]$ with $\bar{\varepsilon} \geq \bar{\varepsilon}^{*}$ a preemptive effort by agent $A$ cannot be optimal. To see this, note that the agent's costs $c(2 \bar{\varepsilon})$ for choosing his preemptive effort increase in $\bar{\varepsilon}$. In the limit, when $\bar{\varepsilon} \rightarrow \infty$, his effort costs are arbitrarily high. According to this result, agents' optimal effort choice in case of a finitely distributed function converges to the case in which the error terms $\varepsilon_{A}$ and $\varepsilon_{B}$ are distributed over an infinite interval. Second, agent $A$ 's incentives to use a preemptive effort are higher the higher his gain from winning the tournament. To see this, note that the left-hand side of inequality (14) increases in $\Delta w$, whereas the right-hand side decreases in $\Delta w$ since $^{9}$

$$
\frac{\partial c\left(e^{*}\right)}{\partial \Delta w}=c^{\prime}\left(e^{*}\right) \cdot \frac{\partial e^{*}}{\partial \Delta w}>0 .
$$

Lazear (1989) showed that from the principal's viewpoint it may be beneficial to choose a low prize spread $\Delta w$ to decrease the agents' incentives for sabotaging each other. Our analysis gives another argument for choosing a low 
$\Delta w$ : By choosing a low prize spread the principal can prevent agent $A$ from exerting preemptive effort, which cannot be preferable from his viewpoint.

The last point becomes obvious, when we consider the principal's decision in stage 1. From Proposition 1 we know that in the case of simultaneous tournaments the principal is able to implement first-best effort by choosing $w_{1}$ and $w_{2}$. According to Proposition 2, in the case of sequential tournaments he faces an additional restriction which may lead away from the first-best solution. In other words, when error is finitely distributed in a sequential tournament, the principal must add the restriction $\Delta w / 2<c(2 \bar{\varepsilon})-c\left(e^{*}\right)$ to his Lagrangian (6). Let $\lambda_{3}$ be the multiplier for this restriction. Then the optimality conditions yield $\lambda_{2}=2$ (i.e., the participation constraint is still binding) and

$$
\lambda_{3}=\frac{4\left(1-c^{\prime}\left(e^{*}\right)\right) f_{Y}(0)}{c^{\prime \prime}\left(e^{*}\right)+2 f_{Y}(0) c^{\prime}\left(e^{*}\right)} .
$$

When $\lambda_{3}>0$, the new restriction is binding and $1>c^{\prime}\left(e^{*}\right)$ is obtained, that is the two agents exert less than first-best effort. However, the first-best solution will be achieved, if the first-best effort $e^{*}=c^{\prime-1}(1)$ and the first-best prizes given by Proposition 1 meet inequality (15). This holds for:

$$
\frac{1}{2 f_{Y}(0)}<c(2 \bar{\varepsilon})-c\left(e^{*}\right),
$$

with $e^{*}=c^{\prime-1}(1)$. The last considerations are summarized in the following proposition:

Proposition 3 When the principal is able to choose between organizing a tournament simultaneously or sequentially, he will weakly prefer a simultaneous tournament, if luck is restricted. There is a critical value $\bar{\varepsilon}^{*}$ with

$$
c\left(2 \bar{\varepsilon}^{*}\right)=\frac{1}{2 f_{Y}(0)}+c\left(c^{\prime-1}(1)\right)
$$


so that for every probability distribution over $[-\bar{\varepsilon}, \bar{\varepsilon}]$ with $\bar{\varepsilon} \geq \bar{\varepsilon}^{*}$ the first-best solution can be achieved in the sequential tournament.

Proposition 3 shows that the critical value $\bar{\varepsilon}^{*}$ depends on the shape of the convolution $f_{Y}(\cdot)$ and the cost function $c(\cdot)$. The concrete value can be easily calculated for a given distribution and a given cost function. Let, for example, $\varepsilon_{A}$ and $\varepsilon_{B}$ be uniformly i.i.d. over the interval $[-\bar{\varepsilon}, \bar{\varepsilon}]$ and let the cost function be quadratic with $c\left(e_{i}\right)=0.5 e_{i}^{2}$. Then we get $\bar{\varepsilon}^{*}=(1+\sqrt{5}) / 4$, because $\bar{\varepsilon}$ and therefore $\bar{\varepsilon}^{*}$ must be positive. ${ }^{10}$

\section{Sequential tournaments without luck}

In this section, we analyze a situation in which only the agents' efforts determine their outputs. Consider first agent $B$ 's decision when choosing his effort at stage 3 . His winning probability can then be specified by

$$
\operatorname{prob}\left\{q_{B}>q_{A}\right\}=\left\{\begin{array}{cl}
1 & \text { if } e_{B}>e_{A} \\
\frac{1}{2} & \text { if } e_{B}=e_{A} \\
0 & \text { if } e_{B}<e_{A}
\end{array}\right.
$$

Suppose that agent $B$ decides to choose $e_{B}>e_{A}$. Since effort is costly, he chooses $e_{B}=e_{A}+\delta$, where $\delta>0$ is an arbitrarily small number. $B$ wins the tournament and his utility is given by $w_{1}-c\left(e_{A}+\delta\right)$. This utility, of course, is greater than the one he receives in case he chooses $e_{B}=e_{A}$ : In this case, his chance to win the tournament is $1 / 2$ so that his expected utility is $\left(w_{1}+w_{2}\right) / 2-c\left(e_{A}\right)$. Since $w_{1}>w_{2}$, there always exists a $\delta>0$ such that

$$
w_{1}-c\left(e_{A}+\delta\right)>\frac{w_{1}+w_{2}}{2}-c\left(e_{A}\right) .
$$

Now suppose that agent $B$ decides to choose $e_{B}<e_{A}$. By the same argument as above, he then chooses $e_{B}=0$ and his utility is given by $w_{2}$. 
Summing up, the reaction function $e_{B}\left(e_{A}, \Delta w\right)$ of agent $B$ can be written as

$$
e_{B}\left(e_{A}, \Delta w\right)=\left\{\begin{array}{cc}
e_{A}+\delta & \text { if } \Delta w>c\left(e_{A}\right) \\
0 & \text { otherwise }
\end{array}\right.
$$

Given this reaction function, agent $A$ decides about his effort choice in stage 2. In principle, he has two choices: He can either choose a preemptive effort to induce $e_{B}=0$ or does not and loses the tournament. In the first case, his optimal preemptive effort $e_{A}$ is given by $c\left(e_{A}\right)=\Delta w$. In the second case, he optimally chooses $e_{A}=0$.

Proposition 4 In the sequential tournament without luck, the agents' optimal behavior is as follows:

(a) Either $e_{B}=0$ and $e_{A}>0$ with

$$
c\left(e_{A}\right)=\Delta w,
$$

(b) or $e_{B}=\delta$ and $e_{A}=0$ with

$$
\delta>0 \text {, arbitrarily small. }
$$

Proposition 4 states that agent $A$ is indifferent between choosing a preemptive effort or dropping out of the tournament. This follows immediately from the fact that his utility is equal in both cases and identical to the loser prize $w_{2}$.

$>$ From the principal's viewpoint at stage 1, a sequential tournament without luck is disastrous. Given the agents participate in the tournament, he can never implement first-best efforts for both agents. The best he could do is to induce the first acting agent to choose an adequate effort level by increasing the prize spread $\Delta w$. Moreover, we can suspect that the problem 
of collusion between the agents will be greater in sequential than in simultaneous tournaments. In a simultaneous tournament, collusions in which the agents agree to reduce their efforts to save effort costs are not stable in general. This is obvious for the simultaneous tournament in Section 2 which has a unique symmetric equilibrium so that any collusive agreement cannot be self-enforcing. Similar considerations hold for a simultaneous tournament without luck. Here, both agents can profitably deviate from a collusive agreement, too. Together, the instability of collusions directly follows from agents' simultaneously choosing their efforts. The situation in sequential tournaments is completely different. Here, agent $A$ chooses his effort first, and he is indifferent between the preemptive effort and dropping out. Therefore, he has no incentive to deviate from the collusion, when both agents have agreed upon $e_{A}=0$. On the other hand, agent $B$ strictly prefers $e_{A}=0$ to $e_{A}>0$, because $w_{1}-c(\delta)>w_{2}$.

Now, consider the principal's maximization problem when choosing the optimal prizes in the sequential tournament without luck. Taking the agents' incentive and participation constraints into account, the Lagrangian function reads as

$$
L\left(w_{1}, w_{2}, e^{*}\right)=e^{*}-w_{1}-w_{2}+\lambda_{1} \cdot\left[\Delta w-c\left(e^{*}\right)\right]+\lambda_{2}\left[w_{2}-\bar{u}\right]
$$

Proposition 5 In a sequential tournament without luck, the principal chooses

$$
w_{2}=\bar{u}
$$

and

$$
w_{1}=\bar{u}+c\left(e^{*}\right)
$$

and implements first-best effort $e^{*}=c^{-1}(1)$ by at most one agent. 
We will now compare these results with the equilibrium behavior in a simultaneous tournament without luck. Note, that different to Proposition 1 in Section 2 the agents do not choose a pure strategy in equilibrium: Suppose that agent $i(i, j=A, B ; i \neq j)$ would choose effort level $e_{i}$ with certainty in equilibrium. To analyze agent $j$ 's best response we can distinguish three cases: First, he can choose $e_{j}<e_{i}$. In this case, he loses the tournament. To minimize his effort costs, he best chooses $e_{j}=0$ and receives a utility $w_{2}$. Second, he can choose the same effort level as agent $i$, that is $e_{j}=e_{i}$. Then prizes are equally split and he receives $\left(w_{1}+w_{2}\right) / 2-c\left(e_{i}\right)$. Third, he overbids agent $i$ and wins the tournament. To avoid too much effort costs, he then best chooses $e_{j}=e_{i}+\delta$, where $\delta$ is positive but arbitrarily small. Since the winner prize is strictly greater than the loser prize, his payoff $w_{1}-c\left(e_{i}+\delta\right)$ is strictly greater than the one in the second case. Together, agent $j$ 's best response function is given by

$$
e_{j}\left(e_{i}\right)=\left\{\begin{array}{cc}
0 & \text { if } e_{i} \geq e_{1} \\
e_{i}+\delta & \text { if } e_{i}<e_{1}
\end{array}\right.
$$

where $e_{1}$ is determined by $\bar{u}=w_{1}-c\left(e_{1}\right)$. Note, that in case of $e_{i} \geq e_{1}$ agent $j$ 's expected utility would be less than his reservation utility $\bar{u}$, if he chooses $e_{j} \geq e_{i}$

We will now argue to a contradiction. Suppose that agent $i$ chooses an effort $e_{i}$ with certainty in equilibrium. If $e_{i}<e_{1}$, he will lose the tournament. Hence, $e_{i}=0$ and agent $j$ wins with an arbitrary small effort $\delta, \delta>0$. But then agent $i$ would win if he chooses an effort level $2 \delta$, a contradiction. If $e_{i} \geq e_{1}$, agent $i$ wins the tournament, hence $e_{i}=e_{1}$. Agent $j$ then chooses no effort, but then agent $i$ would minimize his effort costs if he takes $e_{i}=\delta$, a contradiction.

As a consequence of this discussion we conclude that both agents choose 
mixed strategies in equilibrium. Suppose agent $i$ chooses a mixed strategy. For an effort level $e_{j}$ let $G_{i}\left(e_{j}\right)$ be the probability that agent $i$ loses the tournament, that is, his effort level actually choosen is lower than $e_{j}$. Then agent $j$ 's expected utility when choosing $e_{j}$ is given by

$$
E U_{j}\left(e_{j}\right)=w_{2}+\Delta w G_{i}\left(e_{j}\right)-c\left(e_{j}\right)
$$

Of course, agent $j$ has to be indifferent between choosing $e_{j}$ and some other effort level. In equilibrium then the following condition must hold:

$$
G_{i}\left(e_{j}\right)=\frac{c\left(e_{j}\right)}{\Delta w} .
$$

Hence, agent $j$ chooses an effort level $e_{j}$ in equilibrium with probability $c^{\prime}\left(e_{j}\right) / \Delta w$, which relates marginal costs to marginal gains of an increase in effort.

Proposition 6 When the principal is able to choose between organizing a tournament simultaneously or sequentially, he will strictly prefer a simultaneous tournament, if effort rather than luck determines the agents' outputs.

Proof. For given prizes $\left(w_{1}, w_{2}\right)$ let $\hat{e}$ be the maximal effort level the agents would choose with positive probability in equilibrium. Then $G_{i}(\hat{e})=$ 1 , hence $\triangle w=c(\hat{e})$.

To prove the proposition suppose that the principal chooses $w_{2}=\bar{u}$ and $w_{1}=c\left(e^{*}\right)+\bar{u}$ such that $\hat{e}=e^{*}$ is the first-best effort level. Then the principal will prefer to organize a simultaneous tournament, if the agents' expected outputs are greater than $e^{*}$, the maximal output in the sequential tournament. Now in the simultaneous tournament, the agents' expected outputs are

$$
2 \int_{0}^{e^{*}} e \frac{c^{\prime}(e)}{\Delta w} d e .
$$


Using the fact that $\triangle w=c\left(e^{*}\right)$ and integrating by parts, we conclude that expected outputs are

$$
\frac{2}{c\left(e^{*}\right)}\left[e^{*} c\left(e^{*}\right)-\int_{0}^{e^{*}} c(e) d e\right] .
$$

This term is greater than $e^{*}$ if

$$
e^{*} c\left(e^{*}\right)>2 \int_{0}^{e^{*}} c(e) d e .
$$

This inequality is always satisfied since the cost function $c(\cdot)$ is convex.

To complete the discussion, we can characterize the optimal solution of the principal's problem in the simultaneous tournament as follows: Incorporating the agents' participation constraint, i.e. $w_{2}=\bar{u}$, and incentive constraint, i.e. $w_{1}=c\left(\hat{e}^{*}\right)+\bar{u}$, his maximization problem reduces to

$$
\max _{\hat{e}^{*}} \frac{2}{c\left(\hat{e}^{*}\right)} \int_{0}^{\hat{e}^{*}} e c^{\prime}(e) d e-c\left(\hat{e}^{*}\right)
$$

Integrating by parts, the maximand is equivalent to

$$
2\left[\hat{e}^{*}-\frac{\int_{0}^{\hat{e}^{*}} c(e) d e}{c\left(\hat{e}^{*}\right)}\right]-c\left(\hat{e}^{*}\right) .
$$

The first order condition reduces to

$$
c\left(\hat{e}^{*}\right)^{2}=2 \int_{0}^{\hat{e}^{*}} c(e) d e .
$$

This condition determines the optimal $\hat{e}^{*}$.

\section{Conclusion}

In this paper, we analyzed sequential tournaments in which preemptive behavior by the first acting agent is possible. We showed that intermediate 
information can destroy the incentives of the agent who acts second, thus making a sequential tournament less attractive for the principal than a simultaneous tournament.

In practice, although tournaments are sequential in general the principal may be able to mimic a simultaneous tournament. To avoid strategic behavior in sequential tournaments, he might be able to separate the agents in different locations. If this is possible they cannot observe each others' efforts. This will make an originally sequential tournament "quasi-simultaneous".

An interesting question remains with respect to the agents' strategic behavior in more general dynamic tournaments: Even if in practice the principal can separate the agents so that their decisions are independent, real tournaments are of repeated nature. That is, the entire tournament consists of several stages and at each stage the agents play a simultaneous tournament. Before the next stage, the agents observe their competitors' efforts in the last stage. From the analysis of this paper, one would expect that if effort rather than luck determines the agents' outputs, strategic behavior by the agents will be possible. This strategic behavior might include a preemptive effort by the first acting agent. It is, however, also possible that leapfrogging might occur: Although one agent is behind in total output, he might choose with some small probability an effort level such that he leaves his competitor behind. 


\section{Appendix}

In Section 3, we analyzed the case in which agent $A$ chooses $e_{A}>2 \bar{\varepsilon}$ so that agent $B$ 's probability of winning the tournament becomes zero. Such kind of preemptive effort will be possible, if $\varepsilon_{A}$ and $\varepsilon_{B}$ are distributed over a finite interval $[-\bar{\varepsilon}, \bar{\varepsilon}]$ (i.e., if luck is restricted): $B$ chooses his effort $e_{B}$ according to the first order condition $\Delta w \cdot f_{Y}\left(e_{A}-e_{B}\right)=c^{\prime}\left(e_{B}\right)$, where $Y$ is distributed over $[-2 \bar{\varepsilon}, 2 \bar{\varepsilon}]$. Therefore, by choosing $e_{A}>2 \bar{\varepsilon}$ agent $A$ can shift $f_{Y}\left(e_{A}-e_{B}\right)$ out of the interval $[-2 \bar{\varepsilon}, 2 \bar{\varepsilon}]$ so that $\Delta w \cdot f_{Y}\left(e_{A}-e_{B}\right)$ and $c^{\prime}\left(e_{B}\right)$ intersect at $e_{B}=0$.

Another kind of preemptive effort would occur, if agent $B$ drops out of the tournament, because exerting a competitive effort level is too costly for him. Then, he would choose $e_{B}=0$ for purely economic reasons. This kind of preemptive effort $\hat{e}_{A}<2 \bar{\varepsilon}$ requires

$$
w_{2}+\Delta w\left[1-F_{Y}\left(\hat{e}_{A}-e_{B}\right)\right]-c\left(e_{B}\right)<w_{2}+\Delta w\left[1-F_{Y}\left(\hat{e}_{A}\right)\right]
$$

where $e_{B}$ is given by

$$
\Delta w f_{Y}\left(\hat{e}_{A}-e_{B}\right)=c^{\prime}\left(e_{B}\right)
$$

The left-hand side of (A1) describes agent B's expected utility when he chooses $e_{B}>0$ according to (A2) as a technically best response to $\hat{e}_{A}$. The right-hand side of (A1) characterizes $B$ 's expected utility when he drops out and chooses $e_{B}=0$. Rearranging (A1) yields

$$
\Delta w F_{Y}\left(\hat{e}_{A}\right)-c\left(e_{B}\right)<\Delta w F_{Y}\left(\hat{e}_{A}-e_{B}\right) .
$$

Inequality (A3) shows that the existence of a preemptive effort level $\hat{e}_{A}<2 \bar{\varepsilon}$ crucially depends on the shape of the distribution function $F_{Y}(\cdot)$ and the cost function $c(\cdot)$. 
Now, consider the typical example of uniformly distributed luck and quadratic costs. Thus, we assume for the rest of the Appendix that $\varepsilon_{A}$ and $\varepsilon_{B}$ are uniformly i.i.d. over $[-\bar{\varepsilon}, \bar{\varepsilon}]$ and $c\left(e_{i}\right)=0.5 k e_{i}^{2}(i=A, B)$ with $k>0$. We can show by contradiction that, in this case, there cannot exist a preemptive effort $\hat{e}_{A}<2 \bar{\varepsilon}$. When luck is uniformly distributed, the convolution $f_{Y}(\cdot)$ is triangular with

$$
f_{Y}(y)=\left\{\begin{array}{cc}
\frac{1}{2 \bar{\varepsilon}}+\frac{y}{4 \bar{\varepsilon}^{2}} & \text { if }-2 \bar{\varepsilon} \leq y \leq 0 \\
\frac{1}{2 \bar{\varepsilon}}-\frac{y}{4 \bar{\varepsilon}^{2}} & \text { if } 0<y \leq 2 \bar{\varepsilon} \\
0 & \text { otherwise }
\end{array}\right.
$$

and

$$
F_{Y}(y)=\left\{\begin{array}{cc}
0 & \text { if } y<-2 \bar{\varepsilon} \\
\frac{y}{2 \bar{\varepsilon}}+\frac{y^{2}}{8 \bar{\varepsilon}^{2}}+\frac{1}{2} & \text { if }-2 \bar{\varepsilon} \leq y \leq 0 \\
\frac{y}{2 \bar{\varepsilon}}-\frac{y^{2}}{8 \bar{\varepsilon}^{2}}+\frac{1}{2} & \text { if } 0<y \leq 2 \bar{\varepsilon} \\
1 & \text { if } y>2 \bar{\varepsilon} .
\end{array}\right.
$$

Therefore, $B$ 's best response $e_{B}$ according to (A2) is

$$
e_{B}=\frac{\left(2 \bar{\varepsilon}-\hat{e}_{A}\right) \Delta w}{4 k \bar{\varepsilon}^{2}-\Delta w}
$$

Using (A5), (A6), and the quadratic cost function, inequality (A3) can be rewritten as: ${ }^{11}$

$$
\begin{aligned}
& \Delta w\left(\frac{\hat{e}_{A}}{2 \bar{\varepsilon}}-\frac{\hat{e}_{A}^{2}}{8 \bar{\varepsilon}^{2}}+\frac{1}{2}\right)-0.5 k\left(\frac{\left(2 \bar{\varepsilon}-\hat{e}_{A}\right) \Delta w}{4 k \bar{\varepsilon}^{2}-\Delta w}\right)^{2} \\
< & \Delta w\left(\frac{\hat{e}_{A}-\frac{\left(2 \bar{\varepsilon}-\hat{e}_{A}\right) \Delta w}{4 k \bar{\varepsilon}^{2}-\Delta w}}{2 \bar{\varepsilon}}-\frac{\left(\hat{e}_{A}-\frac{\left(2 \bar{\varepsilon}-\hat{e}_{A}\right) \Delta w}{4 k \bar{\varepsilon}^{2}-\Delta w}\right)^{2}}{8 \bar{\varepsilon}^{2}}+\frac{1}{2}\right) \\
\Longleftrightarrow & -\frac{1}{8} \frac{\left(2 \bar{\varepsilon}-\hat{e}_{A}\right)^{2} \Delta w^{2}}{\bar{\varepsilon}^{2}\left(\Delta w-4 k \bar{\varepsilon}^{2}\right)}<0 .
\end{aligned}
$$


To check inequality (A7) we have to notice that, for uniformly distributed luck and a quadratic cost function, the symmetric Nash effort $e^{*}$ is given by

$$
e^{*}=\frac{\Delta w}{2 \bar{\varepsilon} k}
$$

Since $e^{*}<2 \bar{\varepsilon}$, we obtain

$$
\Delta w<4 k \bar{\varepsilon}^{2}
$$

which implies that (A7) cannot be true.

This leads to the result that in the sequential tournament, in which luck is uniformly distributed over $[-\bar{\varepsilon}, \bar{\varepsilon}]$ and effort costs are quadratic, there does not exist a preemptive effort $\hat{e}_{A}<2 \bar{\varepsilon}$. 


\section{Footnotes}

1. See, e.g., Lazear and Rosen (1981), Nalebuff and Stiglitz (1983), Green and Stokey (1983), O'Keefe, Viscusi, and Zeckhauser (1984), Malcomson (1984, 1986), Rosen (1986), McLaughlin (1988), Lazear (1989).

2. There are some parallels to the literature about preemptive takeover bidding (see, for example, Fishman 1988, 1989), and about R \& D races (see, for example, Fudenberg et al. 1983; Fudenberg and Tirole 1985). These models, however, completely differ from the tournament model which will be analyzed in this paper.

3. By the assumption of unverifiable outcomes we rule out the possibility that the principal can induce proper incentives by using individual incentive schemes like piece rates.

4. Note that the existence of the equilibrium cannot be guaranteed, because the second order conditions are ambiguous. This problem is well-known in the tournament literature; see, for example, Lazear and Rosen (1981, p. 845, fn.2), Nalebuff and Stiglitz (1983, p. 29), Lazear (1989, p. 565, fn. 3).

5. First best effort is described by $e^{*}=\arg \max _{e}(E[e+\varepsilon]-c(e))$, which leads to $e^{*}=c^{\prime-1}(1)$. For this result, which also holds for unrestricted luck (i.e., $\left.\varepsilon_{i} \epsilon(-\infty, \infty)\right)$, see Lazear and Rosen (1981, pp. 844-846); Wolfstetter (1999, pp. 304-306).

6. The integrand directly follows from the rules for the distribution of the difference of two random variables [(see, e.g. Mood, Graybill, and Boes (1974, pp. 185-186)] and the fact that $\varepsilon_{A}$ and $\varepsilon_{B}$ are i.i.d.. The limits of the two integrals stem from the following considerations: The random variable $Y=\varepsilon_{j}-\varepsilon_{i}(i, j=A, B ; i \neq j)$ is distributed over $[-2 \bar{\varepsilon}, 2 \bar{\varepsilon}]$ which can be divided into the two subintervals $-2 \bar{\varepsilon} \leq y \leq 0$ and $0<y \leq 2 \bar{\varepsilon}$. The relations $-\bar{\varepsilon} \leq \varepsilon_{j} \leq \bar{\varepsilon}$ and $\varepsilon_{i}=\varepsilon_{j}-y$ and $y-\bar{\varepsilon} \leq \varepsilon_{j} \leq y+\bar{\varepsilon}$ then lead to 
the expression (7).

7. To be more precise $e_{B}=0$ is obtained for $e_{B}-e_{A}>2 \bar{\varepsilon}$ or $e_{B}-e_{A}<$ $-2 \bar{\varepsilon}$. The first inequality cannot be met by non-negative efforts. The second inequality is identical with (10). Note that we implicitly assume here that the variance of the random variable $\varepsilon_{i}$ is sufficiently high such that a preemptive effort by agent $\mathrm{A}$ implies $e_{A}>2 \bar{\varepsilon}$. This is justified by the fact that in this section we only analyze the implication of restricted luck. Moreover, for the case of uniformly distributed luck and a quadratic cost function it is shown in the Appendix that there does not exist another preemptive effort. In general, if the agents' outputs are determined by effort rather than luck, a preemptive effort $e_{A} \leq 2 \bar{\varepsilon}$ is possible, of course. This case, however, is analyzed in the next section.

8. In the strict sense, $e_{A}$ has to be sligthly above $2 \bar{\varepsilon}$. Greater effort would imply a waste in effort costs.

9. The inverse of the marginal cost function, $c^{\prime-1}(\cdot)$, is monotonely increasing because of $c^{\prime \prime}(\cdot)>0$.

10. Note that here $e^{*}=1$ and $f_{Y}(0)=1 /[2 \bar{\varepsilon}]$, i.e. the probability term $f_{Y}(0)$ itself depends on the critical value.

11. Note, that $\hat{e}_{A}>e^{*}$ must hold for a preemptive effort of agent $A$, where $e^{*}$ is the symmetric Nash effort described in Proposition 2 with $\Delta w f_{Y}(0)=$ $c^{\prime}\left(e^{*}\right)$. Since $e_{B} \neq \hat{e}_{A}$ and $f_{Y}(y)$ has a unique maximum at $y=0$ (see (A4)), we obtain $f_{Y}\left(\hat{e}_{A}-e_{B}\right)<f_{Y}(0)$ and therefore $e_{B}<e^{*}$. This leads to $e_{B}<\hat{e}_{A}$. Thus, the third case in (A5) becomes relevant when rewriting inequality (A3). 


\section{References}

Fishman, M. J. (1988), A theory of preemptive takeover bidding. Rand Journal of Economics 19, 88-101.

Fishman, M. J. (1989), Preemptive bidding and the role of the medium of exchange in acquisitions. Journal of Finance 44, 41-57.

Fudenberg, D., Gilbert, R., Stiglitz, J. E., and J. Tirole (1983), Preemption, leapfrogging and competition in patent races. European Economic Review 22, 3-31.

Fudenberg, D., and J. Tirole (1985), Preemption and rent equalization in the adoption of new technology. Review of Economic Studies 52, 383401.

Green, J. R., and N. L. Stokey (1983), A comparison of tournaments and contracts. Journal of Political Economy 91, 349-364.

Jost, P.-J. (2000), Sequential tournaments. Manuscript.

Lazear, E. P. (1989), Pay equality and industrial politics. Journal of Political Economy 97, 561-580.

Lazear, E.P., and S. Rosen (1981), Rank-order tournaments as optimum labor contracts. Journal of Political Economy 89, 841-864.

Malcomson, J.M. (1984), Work incentives, hierarchy, and internal labor markets. Journal of Political Economy 92, 486-507.

Malcomson, J.M. (1986), Rank-order contracts for a principal with many agents. Review of Economic Studies 53, 807-817. 
McLaughlin, K.J. (1988), Aspects of tournament models: A survey. Research in Labor Economics 9, 225-256.

Mood, A. M., Graybill, F. A., and D. C. Boes (1974), Introduction to the theory of statistics. Third edition. Singapore.

Nalebuff, B. J., and J. E. Stiglitz (1983), Prizes and incentives: toward a general theory of compensation and competition. Bell Journal of Economics 14, 21-43.

O’Keefe, M., Viscusi, W. K., and R. J. Zeckhauser (1984), Economic contests: Comparative reward schemes. Journal of Labor Economics 2, $27-56$.

Rosen, S. (1986), Prizes and incentives in elimination tournaments. American Economic Review 76, 701-715.

Wolfstetter, E. (1999), Topics in Microeconomics. Cambridge. 


\begin{tabular}{|c|c|c|c|}
\hline $\begin{array}{l}\text { Principal } \\
\text { chooses } w_{1} \\
\text { and } w_{2}\end{array}$ & $\begin{array}{l}\text { agent } i(i=A, B) \\
\text { chooses } e_{i}\end{array}$ & $\begin{array}{c}q_{A} \text { and } q_{B} \\
\text { are } \\
\text { realized }\end{array}$ & $\begin{array}{l}\text { agents } \\
\text { receive } w_{1} \\
\text { and } w_{2}\end{array}$ \\
\hline
\end{tabular}

Stage $1 \quad$ Stage 2

Figure 1: Simultaneous tournament.

$\begin{array}{ccccc}\begin{array}{c}\text { Principal } \\ \text { chooses } w_{1} \\ \text { and } w_{2}\end{array} & \begin{array}{c}\text { agent } A \\ \text { chooses } e_{A}\end{array} & \begin{array}{c}\text { agent } B \\ \text { observes } e_{A} \\ \text { and chooses } e_{B}\end{array} & \begin{array}{c}q_{A} \text { and } q_{B} \\ \text { are } \\ \text { realized }\end{array} & \begin{array}{c}\text { agents } \\ \text { receive } w_{1} \\ \text { and } w_{2}\end{array} \\ \end{array}$

$\begin{array}{lll}\text { Stage } 1 & \text { Stage } 2 & \text { Stage } 3\end{array}$

Figure 2: Sequential tournament. 


\section{IZA Discussion Papers}

No. Author(s)

61

62

R. Winkelmann

A. Thalmaier

63

M. Ward

64

M. Ward

65

H. Lehmann

J. Wadsworth

A. Acquisti

66

E. J. Bird

H. Kayser

J. R. Frick

G. G. Wagner

67 R. T. Riphahn

A. Thalmaier

68

B. Dietz

69

M.-S. Yun

70

I. N. Gang

F.L. Rivera-Batiz

71 L. Goerke

72 J. Fersterer

R. Winter-Ebmer

73 G. S. Epstein

S. Nitzan

74 M. Kräkel

75 B. Henry

M. Karanassou

D. J. Snower

76 G. Brunello

M. Giannini

77
Title

Immigration: The New Zealand Experience

Bestimmungsgründe von Fehlzeiten: Welche

Rolle spielt die Arbeitslosigkeit?

Your Everyday, Average Academic

Salary and the Gender Salary Gap in the

Academic Profession

Grime and Punishment: Job Insecurity and Wage

Arrears in the Russian Federation

The Immigrant Welfare Effect: Take-Up or

Eligibility?

Behavioral Effects of Probation Periods:

An Analysis of Worker Absenteeism

Ethnic German Immigration from Eastern Europe and the former Soviet Union to Germany: the Effects of Migrant Networks

Generalized Selection Bias and the Decomposition 6 of Wage Differentials

Immigrants and Unemployment in the European 1

Community

The Wedge

Are Austrian Returns to Education Falling Over

Time?

The Endogenous Determination of Minimum Wage 3

Strategic Mismatches in Competing Teams

Adjustment Dynamics and the Natural Rate: An 1

Account of UK Unemployment

Selective Schools

Knowing What Works: The Case for Rigorous

Program Evaluation
3

5

5

6

Area Date

1

10/99

10/99

10/99

$10 / 99$

10/99

10/99

10/99

$11 / 99$

$11 / 99$

$11 / 99$

$11 / 99$

$11 / 99$

$11 / 99$

$12 / 99$

$12 / 99$

12/99

12/99 
Entrepreneurship from Scratch: Lessons on the

Transition Economies

80 J. C. van Ours

J. Veenman

81 T. J. Hatton

S. Wheatley Price

82 K. A. Konrad

83 R. Euwals

The Netherlands: Old Emigrants - Young

Privacy, time consistent optimal labor income 
M. Rosholm

N. Smith

An Extension of Mortensen and Pissarides (1994)

Ownership or Performance: What Determines

Job Tenure of Two Cohorts of Young German Men 1979 - 1990: An analysis of the (West-)German

Employment Statistic Register Sample concerning multivariate failure times and unobserved heterogeneity

107 J. C. van Ours

Fast Track or Failure: A Study of the Completion 

115 A. Cigno
F. C. Rosati
116 C. Belzil

A. Haas

C. Klose

118 M. A. Shields

M. E. Ward

119 A. Lindbeck

D. J. Snower

120 P. T. Pereira

P. S. Martins

121 J. C. van Ours
117 S. Bender

Why do Indian Children Work, and is it Bad for

3 Them?

Unemployment Insurance and Subsequent Job

Duration: Job Matching vs. Unobserved

Heterogeneity

IAB Employment Subsample 1975-1995.

Opportunities for Analysis Provided by the

Anonymised Subsample

Improving Nurse Retention in the British National Health Service: The Impact of Job Satisfaction on Intentions to Quit

The Division of Labor and the Market for

Organizations

Does Education Reduce Wage Inequality?

Quantile Regressions Evidence from Fifteen

European Countries

Do Active Labor Market Policies Help Unemployed $\quad 4 / 6$ Workers to Find and Keep Regular Jobs?

Returns to Human Capital under the Communist

Wage Grid and During the Transition to a Market

J. Svejnar

K. Terrell

123 J. Hunt

124 R. T. Riphahn

125 F. Büchel

J. R. Frick

126 J. Fersterer

R. Winter-Ebmer

127 M. Karanassou

D. J. Snower

128

O. Ashenfelter

D. Ashmore

O. Deschênes

129 B. R. Chiswick

M. E. Hurst

130 G. Brunello

S. Comi

C. Lucifora

131 B. R. Chiswick
Economy

Why Do People Still Live in East Germany? 1

$3 / 00$

Rational Poverty or Poor Rationality? The Take-up 3

$3 / 00$

of Social Assistance Benefits

The Income Portfolio of Immigrants in Germany - $\quad 1 / 3 \quad 3 / 00$

Effects of Ethnic Origin and Assimilation. Or:

Who Gains from Income Re-Distribution?

Smoking, Discount Rates, and Returns to

Education

Chain Reaction Approach

Do Unemployment Insurance Recipients Actively

Seek Work? Evidence From Randomized Trials in

Four U.S. States

The Employment, Unemployment and

Unemployment Compensation Benefits of Immigrants

$5 \quad 3 / 00$

3

$3 / 00$

6

$3 / 00$

The Returns to Education in Italy: A New Look at

the Evidence

$1 / 3$

$3 / 00$

Are Immigrants Favorably Self-Selected? An

Economic Analysis
Characteristics of Unemployment Dynamics: The 
Hours and Wages in the Depression: British Engineering, 1926-1938

133 D. N. F. Bell

R. A. Hart

O. Hübler

W. Schwerdt

134 A. D. Kugler

G. Saint-Paul

135 A. Barrett

P. J. O'Connell

136 M. Bräuninger

M. Pannenberg

137 J.-St. Pischke

138 J. Zweimüller

R. Winter-Ebmer

139 R. A. Hart

Y. Ma

140 G. Brunello

S. Comi

141 R. Hujer

M. Wellner

142 J. J. Dolado

F. Felgueroso

J. F. Jimeno

143 P. J. Luke

M. E. Schaffer

144 G. Saint-Paul

145 M.-S. Yun

146 T. K. Bauer

J. P. Haisken-DeNew

147 M. Belot

J. C. van Ours

148 L. Goerke

149 R. Lalive

J. C. van Ours

J. Zweimüller
Paid and Unpaid Overtime Working in Germany and 1 the UK

$3 / 00$

Hiring and Firing Costs, Adverse Selection and

3

$3 / 00$

Long-term Unemployment

Is There a Wage Premium for Returning Irish

1

$3 / 00$

Migrants?

Unemployment and Productivity Growth: An

3

$3 / 00$

Empirical Analysis within the Augmented Solow

Model

Continuous Training in Germany

$3 / 00$

Firm-specific Training: Consequences for Job

$3 / 00$

Mobility

Wages, Hours and Human Capital over the

Life Cycle

Education and Earnings Growth: Evidence from $11 \quad 2 / 5 \quad 4 / 00$

European Countries

The Effects of Public Sector Sponsored Training on

Individual Employment Performance in East

Germany

Explaining Youth Labor Market Problems in Spain: 3

Crowding-Out, Institutions, or Technology Shifts?

$4 / 00$

Wage Determination in Russia: An Econometric 4

Investigation

Flexibility vs. Rigidity: Does Spain have the worst of 1 both Worlds?

Decomposition Analysis for a Binary Choice Model

Employer Learning and the Returns to Schooling

Does the Recent Success of Some OECD

Countries in Lowering their Unemployment Rates

Lie in the Clever Design of their Labour Market

Reforms?

Employment Effects of Labour Taxation in an Efficiency Wage Model with Alternative Budget Constraints and Time Horizons

The Impact of Active Labor Market Programs and Benefit Entitlement Rules on the Duration of Unemployment
7

$4 / 00$

5

$4 / 00$

$4 / 00$

$4 / 00$

$3 \quad 4 / 00$

3

$5 / 00$

$3 / 6 \quad 5 / 00$ 
J.-St Pischke

151 M. Ward

152 J. J. Dolado

F. Felgueroso

J. F. Jimeno

153 A. S. Kalwij

M. Gregory

154 Michael Gerfin Michael Lechner

155

J. Hansen

156

C. Dustmann

F. Fabbri

157 P. Apps

R. Rees

158
A. Björklund
T. Eriksson
M. Jäntti
O. Raaum
E. Österbacka

159 P.- J. Jost

M. Kräkel
Gender, Salary and Promotion in the Academic 5 Profession

The Role of the Minimum Wage in the Welfare 3

State: An Appraisal

Overtime Hours in Great Britain over the Period 3

$5 / 00$

1975-1999: A Panel Data Analysis

Microeconometric Evaluation of the Active Labour 6

Market Policy in Switzerland

The Duration of Immigrants' Unemployment Spells: $\quad 1 / 3$

$5 / 00$

Evidence from Sweden

Language Proficiency and Labour Market Per- 1

$5 / 00$

formance of Immigrants in the UK

Household Production, Full Consumption and

7

$5 / 00$

the Costs of Children

Brother Correlations in Earnings in Denmark, 5

Finland, Norway and Sweden Compared to the

$5 / 00$

United States

Preemptive Behavior in Sequential Tournaments

5
$5 / 00$

$5 / 00$

$5 / 00$

$5 / 00$ 